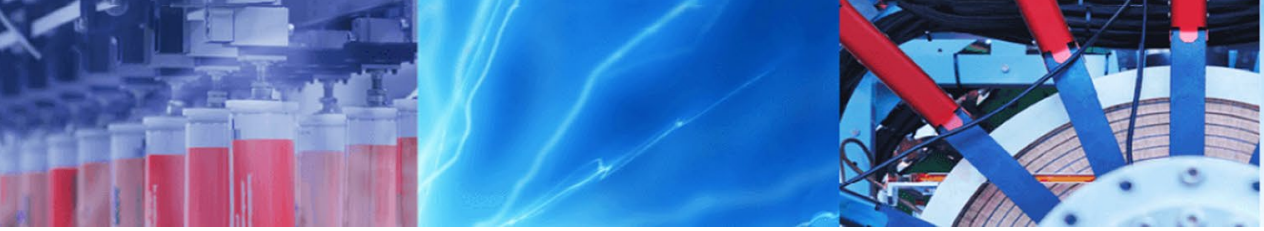

Research Article

\title{
Integrated modelling of hot forging of low-alloyed steels for an ICME workflow
}

\author{
Danish Khan ${ }^{1}$. Pramod Zagade ${ }^{1}$ - B. P. Gautham ${ }^{1}$
}

(c) Springer Nature Switzerland AG 2019

\begin{abstract}
One of the key aspects of integrated computational materials engineering approach is the integrated modelling of process chains that capture the essential microstructure physics and predict the final properties. In the current work, such an integrated modelling approach is attempted for analyzing the hot forging process for low-alloyed steels. Traditionally, hot forging process is designed with primary focus on the deformation step, with less attention paid to the incorporation of microstructure information flow between its sub-steps of heating, deformation and cooling. Such a siloed approach restricts its integration with other manufacturing processes, and also with design and material selection stages. To address the issue, in this work, a FEM based thermo-mechanical modelling framework, integrating composition dependent microstructure evolution models for heating, deformation and cooling sub-steps, is implemented for hot forging of low-alloyed steels. The evolution of key microstructural features at each sub-step is tracked and fed to the following step. The integrated modelling framework is then used to study the effect of process parameters and macrosegregation in the billet on the distribution of final microstructure and properties obtained for a sample steel upsetting process. Key observations made in the studies are discussed. Ways of representation of the distribution of microstructure and properties across the forged part, that can enable better decision making in the larger perspective of downstream processing and final use, are highlighted. Consequently, the utility of the integrated modelling approach to aid the development of improved process and product design capabilities for hot forged products is established.
\end{abstract}

Keywords ICME $\cdot$ Hot forging $\cdot$ Integrated process chain $\cdot$ Microstructure distribution

\section{Introduction}

Hot forging operation, comprising heating, deformation and cooling as its sub-steps, is an important process in the manufacturing-route of various steel finished and semifinished products. It involves various underlying physical phenomena that control the microstructure and hence, the properties of the material. Therefore, to obtain the desired properties, it is necessary to carefully design the process to yield the required microstructure distribution in the final product. Traditionally, process design in the context of hot forging has majorly been limited to address issues such as die designing [1, 2], reducing underfill [3], avoiding possible defects [4-6], flash design [7-9], forging load [10-12] and more recently microstructure evolution [13-17]. Often, these approaches focus primarily on the deformation sub-step design without paying much attention on the role of the process in the larger product development workflow which includes material selection, other upstream and downstream processes and final property requirement. Such kind of siloed approach restricts the possibilities of engineering the quality of the final product through manufacturing process design. Since the final microstructure in the product depends on the composition of the steel and its processing history, every manufacturing process needs to be designed in an integrated

Danish Khan, danishkhan.itbhu@gmail.com | 1 TCS Research, TRDDC, Tata Consultancy Services, 54-B Hadapsar Industrial Estate, Hadapsar, Pune 411013, India.

SN Applied Sciences (2019) 1:1358 | https://doi.org/10.1007/s42452-019-1380-9

Received: 2 July 2019 / Accepted: 27 September 2019 / Published online: 9 October 2019 
fashion by taking into consideration the selected material composition, upstream and downstream processes, and the desired microstructure and property distribution. In the case of hot forging, the process should be designed by taking into account the effect of upstream processes e.g. casting or rolling, and also by evaluating its effect on downstream process, e.g. machining, etc. Within the hot forging process itself, the sub-steps of heating, deformation and cooling needs to be designed in tandem in order to obtain required post-forging microstructure. Such an integrated approach can enable the selection of appropriate material and the corresponding manufacturing process set-points that can result in the desired microstructure distribution in the final product. One of the ways of achieving an integrated approach of process design is through the integrated process chain modelling under ICME (integrated computational materials engineering) workflow [18]. As per this approach, composition-dependent microstructure evolution material models are used in different process and sub-steps models of the process chain. The incorporation of microstructure and its information flow between different process and design models can serve as the underlying unifying theme that can bring about an integrated approach of product development.

In the context of hot forging process design, an important concern in regards to product quality is that the process results in inhomogeneous microstructure and property distribution across the forged part. Each material point inside the forging billet undergoes different strain, strain rate and temperature history dependent upon its location in the part. This results in the formation of different microstructural features across the forged part and leads to a variation of properties across it. This has also been experimentally reported well in literature. For instance, Mkaddem et al. [19] reported the formation of two zones of fine and coarse grains regions in the steel forging resulting from the different extent of deformation that each zone experienced. Similarly, Taherizadeh et al. [20] found the final ferrite grains to be coarse at the centre and fine at the surface for solid forgings and attributed this to the non-uniform distribution of temperature and deformation during the processing. Irani and Taheri [21] analyzed the microstructural homogeneity in the precision forged steel spur gears and found that ferrite grain size and hardness vary from the surface of the gear to the centre. They studied the effect of processing conditions to find the optimum process window for obtaining minimum inhomogeneity across the gear teeth. Apart from the hot forging processing conditions, effect of upstream processes such as casting can also cause the variation of microstructure and properties across the final forged parts. Macrosegregation is a major problem that occurs during the casting of the billets and ingots, which can further lead to variation in mechanical properties of the final forged products. Experimental studies have been carried out to study the variation in microstructure and mechanical properties of large forgings caused due to macrosegregation, with some of them making suggestions to minimize this variation [22-24]. Thus, it becomes clear that, in order to obtain a controlled product quality, the final distribution of microstructure and properties across the forgings should serve as an important criterion while deciding the process set points, and therefore the process design strategy should be able to address it.

Keeping aforementioned issues in mind, this work is an attempt to implement an integrated modelling approach for hot-forging of low alloyed steels and to highlight its importance by using it in analyzing the effect of different process and material conditions, which are otherwise difficult to explore with the traditional siloed approach. To this end, an integrated FEM based modelling framework is implemented for hot forging process by integrating individual models of its sub-steps using chemical composition dependent microstructure evolution models already reported in the literature. These models have been reported to be valid for a wide range of low alloyed steels. In order to establish the integration, the key microstructural phenomena involved in the sub-steps of heating, deformation and cooling are captured in the material models of their individual FEM models. Then the microstructural information flow between these FEM models is established, leading to the development of an integrated modelling framework. To demonstrate the efficacy of the integrated modelling approach, the framework is used in two exploratory case-studies: (1) Study of the effect of process parameters such as heat-soak time, forging temperature, forging velocity on the distribution of final microstructure and properties across the forging and (2) Study of the effect of macrosegregation in the incoming billet on the variation of the microstructure and properties across the forging. To address the issue of material inhomogeneity resulting from hot forging process, and to make it an important criterion in the product development workflow, a novel method to represent the relative distribution of microstructure and properties across the bulk of the product has been developed and used in this work. For brevity purposes and for focusing primarily on the effect of process and material conditions, a simple case of hot upsetting of a sample steel cylindrical billet has been analyzed in this work. Various trends obtained in the microstructure and property variation due to process and material variation are discussed. Wherever possible, the trends predicted by the simulation studies are qualitatively backed up with the experimental findings reported in the literature. 


\section{Modelling of microstructure evolution}

Figure 1 shows a typical hot forging process cycle, highlighting the key microstructural phenomena associated at each stage. The following sub-sections describe the various microstructural changes modelled in this work for each of the sub-steps.

\subsection{Austenitization and grain growth (heating and soaking)}

Austenitization is assumed to get completed once the $\mathrm{Ae}_{3}$ temperature is reached during heating of the billet. $A e_{3}$ is calculated using a chemical composition dependent expression given in Eq. (1) [25]:

$$
\begin{aligned}
\mathrm{Ae}_{3}\left({ }^{\circ} \mathrm{C}\right)= & 912-203 \sqrt{\mathrm{C}}-15.2 \mathrm{Ni}+44.7 \mathrm{Si}+104 \mathrm{~V} \\
& +31.5 \mathrm{Mo}+13.1 \mathrm{~W}-30 \mathrm{Mn}-11 \mathrm{Cr} \\
& -20 \mathrm{Cu}+700 \mathrm{P}+400 \mathrm{Al}+120 \mathrm{As}+400 \mathrm{Ti}
\end{aligned}
$$

where the amount of each of the element is expressed in weight percentage (wt\%). The austenite grain growth kinetics for low-alloyed steels is modelled using the following chemical composition dependent power law, given by Lee and Lee [26]:

$D=K_{o} e^{\frac{-Q_{g}}{R(T+273)}} t^{n}$

- Dynamic recrystallization - Flow stress evolution

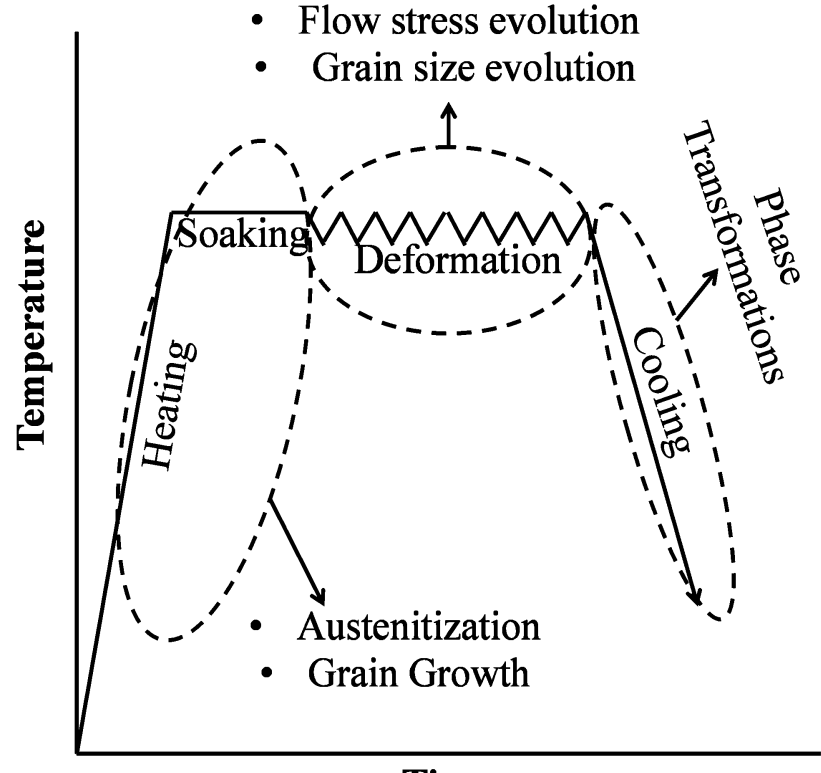

\section{Time}

Fig. 1 Typical hot forging process highlighting essential microstructure physics where $D$ is the austenite grain diameter in $\mu \mathrm{m}, K_{o}$ is a preexponential constant with a value of $76671, n$ is the exponent having a value of $0.211, R$ is the gas constant, $T$ is temperature in ${ }^{\circ} \mathrm{C}, t$ is the time in seconds and $Q_{g}$ is the activation energy for grain growth in $\mathrm{J} / \mathrm{mol}$. $Q_{g}$ is expressed in terms of chemical composition, as follows:

$Q_{g}(J / m o l)=89098+3581 \mathrm{C}+1211 \mathrm{Ni}+1443 \mathrm{Cr}+4031 \mathrm{Mo}$

\subsection{Flow stress, dynamic recrystallization and grain-size evolution (deformation)}

Flow stress and DRX are modelled using chemical composition based equations for low alloyed and microalloyed steels, as given by Hernandez et al. [27] and Medina and Hernandez [28].

As per this model, flow stress $(\sigma)$, as stated in Eq. (4), is expressed as the superposition of two terms: (1) $\sigma_{W+R}$, which is the flow stress value when work-hardening and dynamic-recovery are the only operative deformation mechanisms and (2) $\Delta \sigma$, which is the additional softening obtained due to DRX when strain becomes greater than the critical strain. Equations (5) and (6) give expressions for both the terms.

$\sigma=\sigma_{W+R}-\Delta \sigma$

$\sigma_{W+R}=B\left(1-e^{-C \varepsilon}\right)^{m}$

$\Delta \sigma=B^{\prime} X$

where $\varepsilon$ is the imposed strain. In Eq. (6), $X$ is the DRX fraction which is as expressed as follows:

$$
\begin{aligned}
X & =1-e^{-\left(k \frac{\varepsilon-a \varepsilon_{p}}{\varepsilon_{p}}\right)^{m^{\prime}}}\left(\text { for } \varepsilon>a \varepsilon_{p}\right) \\
& =0\left(\text { for } \varepsilon<a \varepsilon_{p}\right)
\end{aligned}
$$

The parameters $B, C, m, B^{\prime}, k, a, \varepsilon_{p}, m^{\prime}$ in the above equations are expressed as functions of the ratio $Z / A$ [27], where $Z$ is the Zener-Hollomon parameter, and $A$ is the multiplier in the Sellars-Tegart equation [29]. $Z$ is expressed as:

$Z=\dot{\varepsilon} e^{\frac{Q_{d}}{R T}}$

where $\dot{\varepsilon}$ is the strain rate, $Q_{d}$ is the activation energy for deformation in $\mathrm{J} / \mathrm{mol}$, and $T$ is the temperature in Kelvin. Both $Q_{d}$ and $A$ are expressed as the functions of chemical composition as follows:

$$
\begin{aligned}
Q_{d}(\mathrm{~J} / \mathrm{mol})= & 267000-2535.52 \mathrm{C}+1010 \mathrm{Mn} \\
& +33620.76 \mathrm{Si}+35651.28 \mathrm{Mo}+93680.52 \mathrm{Ti}^{0.5919} \\
& +31673.46 \mathrm{~V}+70729.85 \mathrm{Nb}^{0.5649}
\end{aligned}
$$


$A\left(\mathrm{~s}^{-1}\right)=(12.197+65.590 C-49.052 \mathrm{Nb}) e^{\left(7.076 \times 10^{-5} Q_{d}\right)}$

In Eq. (7), $\varepsilon_{p}$ is the peak-strain and is expressed as follows:

$\varepsilon_{p}=B_{o} D^{p 1}\left(\frac{Z}{A}\right)^{p 2}$

where $B_{o}, p 1, p 2$ are the parameters dependent on the type of steel and $D$ is the initial austenite grain size. The incorporation of the effect of initial austenite grain size on the peak strain makes it possible to take the dependence of the state of material prior to hot deformation on the flow and microstructure evolution during hot deformation. Further details about the model are available elsewhere [27, 28] and are not reproduced here.

In order to take into account the non-iso-strain rate and non-isothermal conditions prevalent during the actual industrial hot forging process, an additivity rule for critical strain $\left(=a \varepsilon_{p}\right)$ is employed to mark the initiation of DRX. The additive rule used is given in Eq. (12), where $\Delta \varepsilon_{i}$ denotes the strain increment for ith increment and $\varepsilon_{p, i}$ denotes the value of $\varepsilon_{p}$ for that increment. Since different strain increments occur at different strain rates, it is justifiable to use such an additive rule in order to include the contribution of each plastic strain increment to the total strain energy needed for the incubation of nuclei for DRX.

$\sum \frac{\Delta \varepsilon_{i}}{a \varepsilon_{p, i}}=1$

Recrystallized grain size is predicted using the expression given by Medina and Hernandez [28]:

$D_{R X}(\mu \mathrm{m})=38.26\left(\frac{Z}{A}\right)^{-0.08}$

Parent austenite grains that deform but do not recrystallize, get pancaked and develop irregularities at the grain boundaries that affect the phase transformation kinetics during cooling. This effect can be captured by defining effective grain size for such grains, as given by Kang and Liu [30], through the following expression.

$D_{e f f}(\mu \mathrm{m})=D e^{-\frac{\varepsilon_{r}}{4}}$

where, $D$ is the initial austenite grain size before deformation and $\varepsilon_{r}$ is the retained strain, taken as $\varepsilon(1-X), X$ being the recrystallized fraction.

A volume average of the size of dynamically recrystallized grains as well as un-recrystallized pancaked grains is used to predict the final average grain size $\left(D_{f}\right)$. Equation (15) shows the expression used for calculation of $D_{f}$, where $D_{R X, i}$ denotes the value of $D_{R X}$ for the ith simulation increment with corresponding recrystallization fraction increment $\Delta X_{i}$, and $X$ denotes the total DRX fraction.
$D_{f}=\left(\sum D_{R X, i} \Delta X_{i}\right)+D_{e f f}(1-X)$

In the present work single step hot forging is addressed and the forged billet is assumed to be cooled (or quenched) rapidly enough such that the post-forging recrystallization mechanisms such as static recrystallization (SRX) and metadynamic recrystallization (MDRX) can be neglected. Thus, neither SRX nor MDRX is modelled in this work.

\subsection{Phase transformation (cooling)}

Austenite transformation to various diffusional phase transformation products while cooling is modelled using the semi-empirical model given by Kirkaldy and Venugopalan [31]. This model expresses the rate of formation of any $k$ th phase $\left(\frac{d X_{k}}{d t}\right)$ in terms of the functions of steel composition $\left(C_{0}\right)$, temperature $(T)$, prior austenite grain size ASTM number $(G)$ and the already formed normalized phase fraction $\left(X_{k}\right)$ (the true fraction, $X_{k}^{T}$, of a phase is normalized with respect to the maximum amount of that phase that can form at that temperature under equilibrium conditions). This is expressed as follows:

$\frac{d X_{k}}{d t}=f_{1}\left(C_{o}\right) f_{2}(G) f_{3}(T) f_{4}\left(X_{k}\right)$

Or,

$d X_{k}=f_{1}\left(C_{o}\right) f_{2}(G) f_{3}(T) f_{4}\left(X_{k}\right) \cdot d t$

Depending on the temperature, the equation for the respective phase is used to calculate the increment in the normalized fraction of the phase $\left(d X_{k}\right)$ for that time increment $(d t)$ as given in Eq. (17). The final phase fraction of each phase at the end of the cooling cycle can be thus calculated by adding up these increments. The details of the form of the functions $f_{1}, f_{2}, f_{3}, f_{4}$ for each of ferrite, pearlite and bainite phases, and the implementation can be found in the literature [31] and hence are not reproduced here.

Martensitic transformation is modelled using the Koistinen-Marbuger equation [32] given as:

$X_{m}^{T}=X_{\gamma-M s}^{T}\left(1-\exp \left(-0.011\left(M_{S}-T\right)\right)\right)$

where $X_{m}^{T}$ is the true fraction of martensite and $X_{\gamma-M s}^{T}$ is the austenite true fraction at $M_{S}$ temperature. In order to model various phase transformations, we need to know the associated start temperatures for each of these phases. Chemical composition dependent expressions, reported in literature, are used for calculating Upper-critical temperature $\left(A e_{3}\right)$ [25], Eutectoid temperature $\left(A e_{1}\right)$ [33], Bainite-start temperature $\left(B_{s}\right)$ [34] and Martensite-start temperature $\left(M_{s}\right)[35]$. 
Final ferrite grain size $\left(D_{\alpha}\right)$ is predicted using Eq. (19), given by Suehiro et al. [36], which predicts $D_{\alpha}(\mu \mathrm{m})$ in terms of initial austenite grain size $\left(D_{f}\right)$, total ferrite fraction $\left(X_{f}^{T}\right)$ and ferrite start temperature, expressed in terms of $5 \%$ transformation, $\left(T_{0.05}\right)$ as follows:

$D_{\alpha}(\mu \mathrm{m})=\left(5.51 \times 10^{10} D_{f}^{1.75} \exp \left(\frac{-21430}{T_{0.05}}\right) X_{f}^{T}\right)^{\frac{1}{3}}$

\subsection{Hardness prediction}

In order to calculate post-forging hardness, carbon content dependent empirical hardness expressions (in terms of VHN) for each phase have been developed in this work using the experimental data available in the literature [37-40]. Following equations give the expressions developed for each of the phases:

$H V_{f}=(98.322 C+78.027)+\frac{(152.9-49.922 C)}{\sqrt{D_{\alpha}}}$

$H V_{p}=229.58 C+101.64$

$H V_{b}=181.8 C+193.8$

$H V_{m}=-807 C^{2}+1452.5 C+226.2$

where $H V_{f}, H V_{p}, H V_{b}, H V_{m}$ are the hardness of ferrite, pearlite, bainite, and martensite respectively, $C$ is the carbon content in $w t \%$, and $D_{\alpha}$ is the ferrite grain size in $\mu m$.

The final hardness of the component is calculated using the rule of mixture as follows:

$H V=H V_{f} X_{f}^{T}+H V_{p} X_{p}^{T}+H V_{b} X_{b}^{T}+H V_{m} X_{m}^{T}$

\section{Finite element implementation and integration of models}

The integrated hot forging modelling framework is developed using a commercial finite element package, ABAQUS, along with the aid of user-subroutines. The sub-routines take the chemical composition of the steel as input. Microstructural features are captured using state dependent variables facilitated by ABAQUS. The framework comprises three models, each corresponding to a sub-step of heating, deformation and cooling of the hot forging process. Heating and forging deformation are modelled using coupled thermomechanical analysis, while only the thermal analysis is carried out for cooling. Heating and cooling are simulated using ABAQUS/Standard while deformation is simulated using ABAQUS/Explicit.
Heating simulation involves complete thermal cycle simulation incorporating heating, soaking and transfer to dies as its inner sub-steps. It is modelled as a transient thermo-mechanical analysis which takes initial geometry of the billet, its thermophysical and mechanical properties and furnace heating conditions as input. The model captures heating of the billet due to convection and radiation, and the associated thermal expansion. Austenite grain growth during heating-soaking, as discussed in Sect. 2.1, is modelled as a field variable in a user-subroutine. At each time-step of the simulation, the increment in temperature is taken as an input to the subroutine for calculating the increment in grain diameter for that time-step. The increment is then added to the austenite grain diameter from the previous step to get the updated austenite grain diameter. Typical heat transfer coefficients for furnace heating are assumed. Heat loss is expected in the process of transferring the billet from furnace to the press and is modelled through appropriate value for heat transfer coefficient.

The subsequent step of deformation is simulated in ABAQUS/Explicit, which takes the final expanded geometry with its associated temperature $(T)$ and austenite grain size $(D)$ distribution from the heating simulation as the input to the model. This simulation involves modelling hot deformation of the billet as well as heat transfer to the dies in a coupled thermo-mechanical model. The temperature, strain and strain-rate dependent flow stress of the steel is modelled using VUHARD subroutine. The microstructural parameters such as dynamically recrystallized fraction and average recrystallized grain size are calculated as state variables in the VUHARD subroutine. For each time-step, the plastic strain-increment and temperature change are taken as input to the sub routine for updating the values of flow stress, recrystallized fraction and average recrystallized grain size, as described in Sect. 2.2. Large deformations can lead to excessive mesh distortions and to take care of this, we use ALE (Lagrangian-Eulerian) adaptive meshing and remapping option [41]. Forging dies are modelled as rigid bodies maintained at a constant temperature. Frictional contact between the billet and dies is modelled using a friction factor of 0.4 , which is a typical value used for hot-forging of steels [16]. Heat transfer between the dies and the billet in the contact region is captured by assigning contact conductance, as a function of pressure and temperature. Contact conductance between surfaces is expressed through contact properties defined in terms of gap clearance. Mechanical contact relationship is expressed in terms of contact pressure varying exponentially with gap clearance. Appropriate values for these simulation parameters were used by taking inputs from the similar metal forming analysis [41]. Temperature dependence is taken through temperature dependent thermophysical material properties. All 
the dissipated energy between billet and die due to friction is assumed to be contributing to interfacial heat generation, which is a typical assumption made in many metal forming analyses [41].

Finally, the cooling step is modelled for thermal and metallurgical aspects in ABAQUS/Standard. The cooling simulation takes the final deformed geometry with its average recrystallized grain size $\left(D_{f}\right)$ and temperature $(T)$ distribution from deformation simulation as the input material state. Heat transfer from the billet to the cooling or quenching media is modelled by applying appropriate heat transfer coefficient and emissivity interaction parameters. Phase fraction evolution, hardness and ferrite grain size prediction are modelled in the UMATHT subroutine. The subroutine takes the change in temperature at each time increment as input from the solver to calculate the change in phase-fractions (as described in Sect. 2.3), which is then cumulatively added to get the final phase fractions. Hardness and ferrite grain size is also calculated using respective equations in the subroutine and stored as state-dependent variables. The phase fractions dependent thermophysical properties, needed for solving heat transfer equations, are also computed in the subroutine.

The information flow between individual sub-step simulations is achieved using ABAQUS python scripting that enables the post-processing of the output files of one simulation to extract the relevant information and preparation of the appropriate files to be read by the next simulation. This microstructural information flow, between simulations of different sub-steps of forging, leads to their integration. Further, it is ensured that the integration of models is not affected by different sub-steps of forging by appropriately mapping the state variables information between meshes of different sub-step simulations. The complete integrated process modelling framework of FEM simulations along with the appropriate information flow between individual sub-steps is shown in the Fig. 2 .

\section{Forging process studies for hot upsetting}

In order to demonstrate the importance of the integrated modelling of hot forging process, the framework has been used to address two studies for a typical case of single-hit, flat-die hot-upsetting of a C-Mn-Mo steel cylindrical billet. The two studies conducted are: (1) studying the effect of various forging process parameters and (2) studying the effect of the macrosegregation in the incoming billet on the resultant microstructure and properties. The composition of the steel is given in Table 1, and the schematic diagram of process cycle highlighting the process parameters and dimensions of the cylindrical billet is shown in Fig. 3 $a, b$ respectively. The cylindrical billet is modelled as a half axisymmetric part in the FE model (as shown by shaded portion in Fig. 3b), and to be forged to $67 \%$ reduction in height. Following sub-sections describe the studies.

\subsection{Effect of process parameters}

Designing the manufacturing route for obtaining the desired properties of the forged component requires exploration of the effect of various process parameters on the final microstructure and properties. This study elucidates the application of the modelling framework for such an activity. In order to study the combined effect of process parameters such as heat-soak time, forging temperature and forging velocity on the final microstructure and property distribution, multiple simulations have been carried out for the complete process cycle at different combinations of these process parameters values. Following are the values of the process parameters used in this study:

- Heat-Soak time ( $t_{\text {soak }}$, in minutes): 100,200

- Forging temperature $\left(T_{\text {forge }}\right.$ in $\left.{ }^{\circ} \mathrm{C}\right): 1000,1100$

- Forging velocity $\left(v_{\text {forge, }}\right.$ in $\left.\mathrm{mm} / \mathrm{s}\right): 10,25,50,75$

These process parameter values have been chosen based on the industrial practices for small-sized forged components. Figure 4 shows the FEM contour plots for the distribution of some of the key results obtained at the end of each sub-step for the case of $t_{\text {soak }}=100 \mathrm{~min}$, $T_{\text {forge }}=1100^{\circ} \mathrm{C}$ and $v_{\text {forge }}=25 \mathrm{~mm} / \mathrm{s}$. It is evident from Fig. $4 \mathrm{~b}$ that there are two prominent regions in the forged part that have either undergone complete recrystallization or no recrystallization at all. This is despite the simple geometry of billet, which is broadly undergoing uniform deformation. This is similar to the experimental findings of Mkaddam et al. [19] who reported the formation of two zones in the forgings that experienced different extents of deformation during processing. Similarly, Fig. $4 \mathrm{~d}$ shows finer ferrite grain size at the surface and coarser grain at the centre, which is similar to the experimental findings of Taherizadeh et al. [20]. As discussed earlier, both the distribution and the homogeneity of final microstructural features and properties should be considered while making appropriate choices for process parameters. Thus, it is important to express the results in a manner which conveys this information. For this, relative distribution plots, expressed in terms of bulk volume fraction, are plotted for microstructural features and properties. In the context of the current work, the microstructural features studied are recrystallized fraction $(X)$, final average austenite grain size $\left(D_{f}\right)$, phase fractions $\left(X_{k}\right)$ and ferrite grain size $\left(D_{\alpha}\right)$, and the property studied is the final hardness $(H V)$. In order to obtain the relative-distribution plots of these results 
from the modelling framework, the relevant information from FEM simulations has been extracted and used. Following procedure details the methodology adopted for obtaining such plots:

1. Value of the result $\left(R_{\text {int }}\right)$ and the associated integrationpoint volume $\left(V_{\text {int }}^{o}\right)$ are extracted from each integration-point of the FEM model.

2. $V_{\text {int }}^{o}$ of each integration point is normalized with respect to the total volume $\left(V_{\text {tot }}^{o}=\sum V_{\text {int }}^{o}\right)$ to get its normalized integration point volume $\left(V_{\text {int }}\right)$.

3. The range of $R_{\text {int }}$ for all the integration points $(\Delta R)$ is binned into the number of bins $(n)$ of interest. This result in the formation of $n$ bins, each representing a different interval $\left(\Delta R_{i}\right)$ of $\Delta R$.

4. Each $R_{\text {int }}$ is then allotted to a particular $\Delta R_{i}$ it belongs to, and its associated $V_{\text {int }}$ is added to the cumulative volume for that bin $\left(V_{i}\right)$.

5. Finally, a distribution plot is plotted between $\Delta R_{i}$ and their $V_{i}$.

Such a relative-distribution plot provides the information on the statistical distribution of the range of the result $\left(\Delta R_{i}\right)$ in terms of bulk volume fraction $\left(V_{i}\right)$ of the total billet volume. In this way, we can not only represent the range of the results obtained under certain process condition, but also the relative distribution over the volume of the billet. For example, from Fig. 5 a we can deduce that, under the prescribed process conditions, around $34 \%$ of the total billet volume undergoes complete recrystallization, $7 \%$ of the billet undergoes no recrystallization, while rest of the volume undergoes partial recrystallization. Such a representation of results can help us decide process parameters which yield homogeneous or acceptable distribution of microstructural features and properties.

Following subsections highlight some of the important effects observed due to variation in different process parameters. Due to a large number of combinations for process parameter values possible, only a few such combinations for prominent results are discussed. Similar effects of a particular process parameters were observed for other combinations as well.

\subsubsection{Effect of heat-soak time $\left(t_{\text {soak }}\right)$}

Increasing heat-soak time $\left(t_{\text {soak }}\right)$ leads to austenite grain growth, which affects the evolution of flow-stress and recrystallized grain size in the subsequent deformation step, which in turn affects the final phase fractions and properties during cooling. Thus the signature of increased $t_{\text {soak }}$ can be seen in all the resultant microstructure features. The effect of $t_{\text {soak }}$ on two such features are discussed. Figure $5 \mathrm{a}, \mathrm{b}$ show relative-distribution plots of recrystallized fraction, for 100 and $200 \mathrm{~min}$ of $t_{\text {soak }}$ respectively, at $T_{\text {forge }}=1000^{\circ} \mathrm{C}$ and $v_{\text {forge }}=25 \mathrm{~mm} / \mathrm{s}$. It can be seen from the distribution that the amount of bulk material undergoing complete recrystallization decreases with increasing $t_{\text {soak }}$ and higher partially recrystallized volume is obtained. This is expected as the longer heat-soak time leads to larger austenite grain size and lower grain boundary area, thereby providing lesser nucleation sites for recrystallized grains and thus retarding the DRX kinetics. On the other hand, Fig. $6 a$, b show the effect of $t_{\text {soak }}$ on final martensite fraction after cooling. Depending upon the final application or further processing of the forged component (such as machining), martensite can be either a desirable or an undesirable component in the final microstructure and thus it is important to know the effect of process parameters on its formation. For example, if hot forging is to be followed by machining operation, the presence of martensite phase on the surface can lead to higher tool wear or crack formation. It can be seen that higher $t_{\text {soak }}$ value leads to relatively higher martensite fractions. This is because of the larger austenite grain size (and thus higher $D_{f}$ ) leads to an increase in hardenability of steels due to the decrease in the grain boundary area, and thus enables the formation of more martensite.

\subsubsection{Effect of forging temperature $\left(T_{\text {forge }}\right)$}

Increasing the forging temperature $\left(T_{\text {forge }}\right)$ will not only lead to higher grain growth during heating-soaking (which will have an impeding effect on DRX) but would also favour enhanced DRX due to high thermal energy available for recrystallization. Also, quenching from a higher $T_{\text {forge }}$ would lead to the development of higher cooling rates in the billet during quenching. Therefore, the final microstructure and properties obtained after quenching will have a complex dependence on $T_{\text {forge. }}$. Figure $7 \mathrm{a}$, $b$ show the dependence of recrystallization fraction on $T_{\text {forge. }}$. It can be seen from the figures that increasing $T_{\text {forge }}$ from 1000 to $1100^{\circ} \mathrm{C}$ leads to enhancement of recrystallization, with an increase in completely recrystallized bulk volume from about $25 \%$ to $60 \%$. In addition, an increase in the recrystallized fraction of partially recrystallized regions, and a decrease in the bulk volume of un-recrystallized regions is observed. On the other hand, Fig. 8 a, b show the effect of $T_{\text {forge }}$ on the final hardness distribution. Final hardness and its uniformity are important characteristics of the final component, which needs to be controlled in order to achieve desired properties. It can be seen that increasing $T_{\text {forge }}$ leads to relatively lower uniform hardness distribution with regions containing higher hardness values as compared to lower forging temperature. This can be explained on the basis of enhanced martensitic transformation that occurs while quenching from a higher $T_{\text {forge }}$. 


\begin{tabular}{|c|c|c|c|c|}
\hline \multirow{3}{*}{$\begin{array}{l}\text { Heating-Soaking } \\
\text { Coupled Thermo- } \\
\text { Mechanical Simulation } \\
\text { in ABAQUS Standard } \\
\text { Austenite Grain Size } \\
\text { Evolution }\end{array}$} & & \multirow{3}{*}{$\begin{array}{l}\text { Deformation } \\
\text { - Coupled Thermo- } \\
\text { Mechanical Simulation } \\
\text { in ABAQUS Explicit } \\
\text { - DRX, Flow stress, } \\
\text { Grain Size evolution } \\
\text { using VUHARD }\end{array}$} & & \multirow{3}{*}{$\begin{array}{l}\text { Cooling } \\
\text { - Thermal Simulation in } \\
\text { ABAQUS Standard } \\
\text { - Phase Transformation } \\
\text { modelling using } \\
\text { UMATHT }\end{array}$} \\
\hline & Geometry & & Geometry & \\
\hline & $D, T$ & & $D_{f}, T$ & \\
\hline
\end{tabular}

Fig. 2 Integrated process modelling framework with associated information flow

Table 1 Chemical composition of the C-Mn-Mo steel used for the two studies

\begin{tabular}{lllll}
\hline Steel & $\mathrm{C}$ & $\mathrm{Si}$ & $\mathrm{Mn}$ & $\mathrm{Mo}$ \\
\hline C-Mn-Mo & 0.44 & 0.23 & 0.79 & 0.38 \\
\hline
\end{tabular}

Martensitic transformation is favoured in austenite grains not only because of the higher average recrystallized grain size but also due to higher cooling rates obtained in case of higher $T_{\text {forge }}$.

\subsubsection{Effect of forging velocity $\left(v_{\text {forge }}\right)$}

Increasing the forging velocity $\left(v_{\text {forge }}\right)$ increases the strainrate during deformation, which increases the critical strain required for initiation of DRX. This leads to a reduction in recrystallization fraction for the same amount of strain applied [Eq. (11)]. Apart from that, the increased strain-rate also leads to finer grain sizes in the completely recrystallized regions [Eq. (13)]. Therefore, the distribution of final average grain size $\left(D_{f}\right)$ after deformation will be decided by the net effect of the $v_{\text {forge }}$. Figure $9 a-d$ show the net effect of increasing forging velocity for one of the cases. It can be seen in general that as the forging velocity increases, the bulk volume corresponding to higher $D_{f}$ values increases. There are two prominent peaks, as observed in the case of $v_{\text {forge }}=10 \mathrm{~mm} / \mathrm{s}$ in Fig. 9a. The first peak, at around 34 $\mu \mathrm{m}$, corresponds to the regions undergoing complete recrystallization, and other at around $55 \mu \mathrm{m}$ corresponds to the regions undergoing no or negligible recrystallization. As discussed before, these two peaks conform to the experimental findings of the formation of two separate zones of different grain sizes in the forgings [19]. Both the peaks decrease with increasing $v_{\text {forge }}$ due to decrease in the volumes corresponding to both the regions. Moreover,
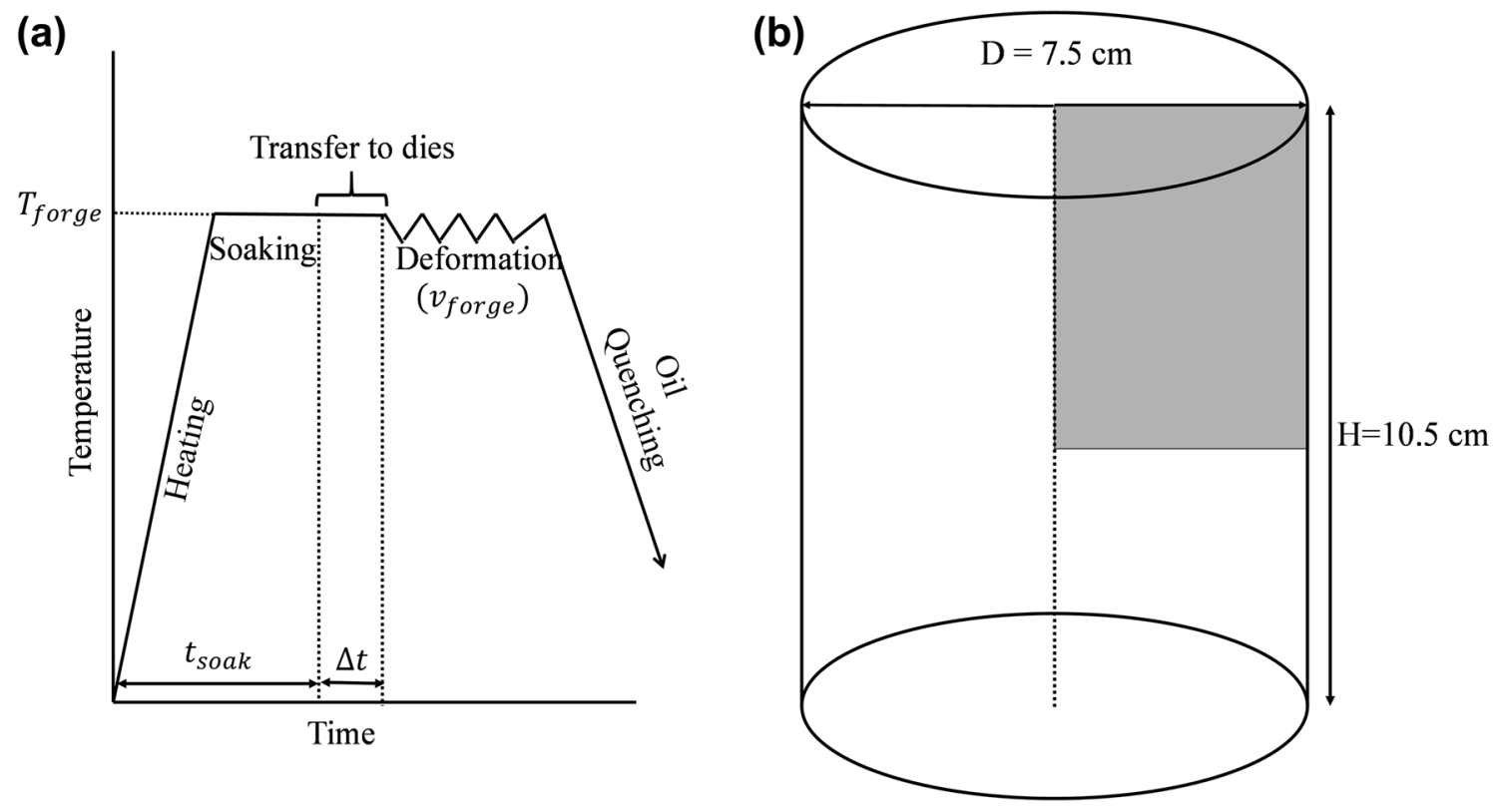

Fig. 3 Details of the hot-forging cycle and billet geometry for the studies: a Schematic of the hot forging cycle simulated highlighting the process parameters considered $\mathbf{b}$ The Cylindrical billet dimensions with shaded portion showing the half axisymmetric part modelled 
the peak for complete recrystallized region gets shifted to smaller grain size, because of the finer grains obtained due to increased strain rate. In addition, it can be observed that increasing $v_{\text {forge }}$ leads to a less uniform distribution of $D_{f}$ due to increase in partially recrystallized regions. On the other hand, it can be seen from Fig. 10a-d that increasing $v_{\text {forge, }}$ though resulted in inhomogeneous $D_{f}$ distribution, leads to increase in uniformity of ferrite grain size $\left(D_{\alpha}\right)$ distribution at the end of cooling. This is in accordance with the experimental findings of Essadiqi and Jonas [42] who studied the effect of hot deformation on ferrite formation during cooling and reported an increase in the homogeneity of ferrite grain structure with increase in strain-rate. Prediction of ferrite grain size is important since it governs the final mechanical properties of the components, and thus knowing its distribution becomes very important to keep the variation in final mechanical properties in control. As it can be seen from Eq. (19), $D_{\alpha}$ not only depends on the initial austenite grain size $\left(D_{f}\right)$ but also on the kinetics of ferrite transformation through the transformation start temperature $\left(T_{0.05}\right)$ and the total ferrite fraction $\left(X_{f}^{T}\right)$. An increase in $D_{f}$ values due to an increase in $v_{\text {forge }}$ leads to retardation of ferrite transformation kinetics, thus lowering of $T_{0.05}$ and $X_{f}^{T}$. Thus the final $D_{\alpha}$ distribution, on increasing $v_{\text {forge }}$ depends on the net effect of increase in $D_{\alpha}$ values due to an increase in $D_{f}$, and a decrease in $D_{\alpha}$ values due to decrease in $T_{0.05}$ and $X_{f}^{T}$.

\subsection{Effect of macrosegregation}

Apart from enabling appropriate choice of process parameters (as demonstrated in Sect. 4.1), being able to incorporate the effect of chemical composition, the modelling framework also enables integration with upstream process of casting by taking the resultant macrosegregation in the billet into account. In order to model the effect of macrosegregation during casting, a typical macrosegregation profile is assumed by taking inputs from the study of Mangal et al. [43]. The carbon and the manganese content of the cylindrical billet are varied radially from the centre to the surface. Figure 11a shows this variation for the $\mathrm{C}-\mathrm{Mn}$-Mo steel, expressed in terms of $r / R$, where $r$ is the radial distance of any point in the cylinder from its axis and $R$ is the radius of the cylinder. The dashed lines in the figure show the nominal carbon and manganese content for the steel. The hot forging process cycle, similar to that as given in Fig. 3a, is simulated for this billet for the (a)
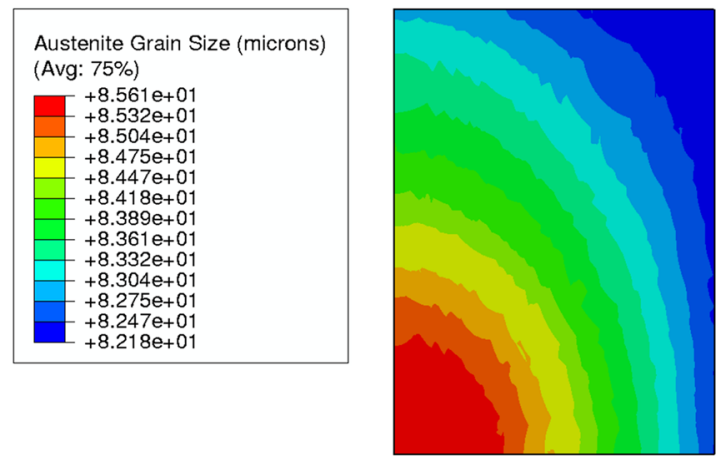

(c)

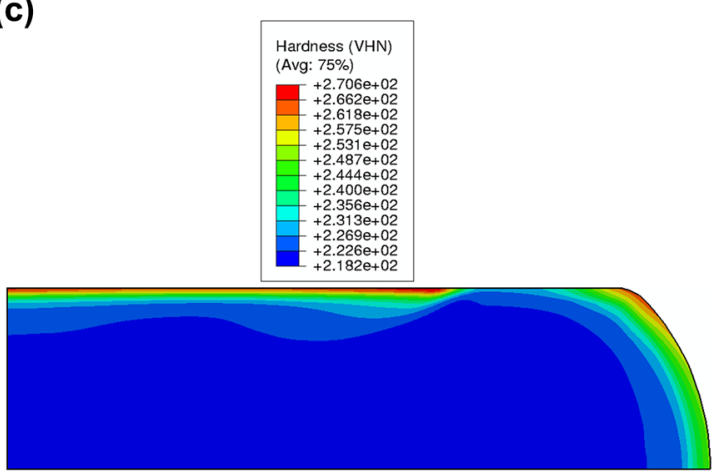

(b)

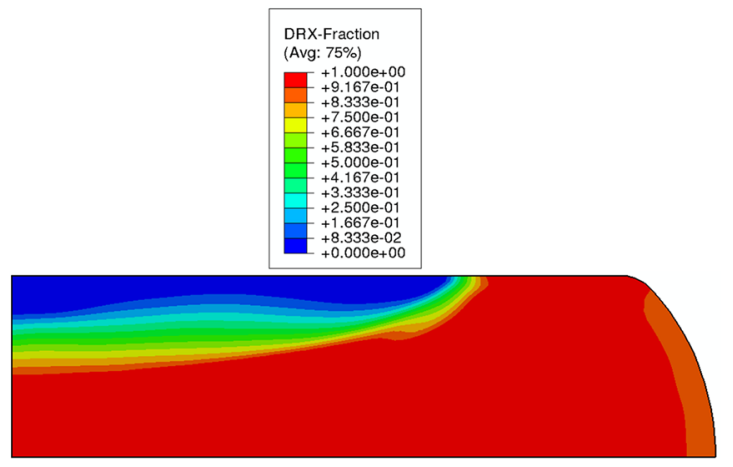

(d)

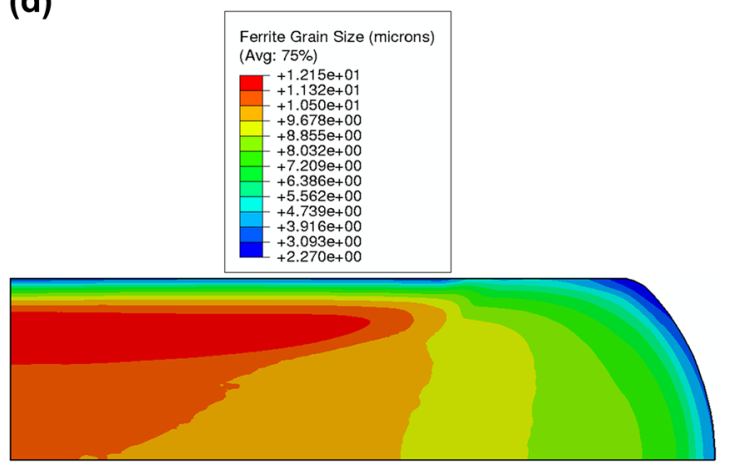

Fig. 4 Contour plots of the distribution of various results in the billet obtained after different sub-steps: a austenite grain size distribution after heat-soak step, b DRX-fraction after deformation step, $\mathbf{c}$ hardness (VHN) and $\mathbf{d}$ ferrite grain size $(\mu \mathrm{m})$ after quenching step 
Fig. 5 Relative-distribution plots for DRX fraction obtained for $1000^{\circ} \mathrm{C}$ forging temperature, $25 \mathrm{~mm} / \mathrm{s}$ forging velocity at different soak times: a 100 min soak times b $200 \mathrm{~min}$ soak time

Fig. 6 Relative-distribution plots for Martensite fraction obtained for $1000^{\circ} \mathrm{C}$ forging temperature, $75 \mathrm{~mm} / \mathrm{s}$ forging velocity at different soak times: a 100 min soak time b $200 \mathrm{~min}$ soak time

Fig. 7 Relative-distribution plots for DRX fraction obtained for $200 \mathrm{~min}$ heat-soak time and $25 \mathrm{~mm} / \mathrm{s}$ forging velocity at different temperatures: $\mathbf{a}$ $1000^{\circ} \mathrm{C} \mathrm{b} 1100^{\circ} \mathrm{C}$ (a)

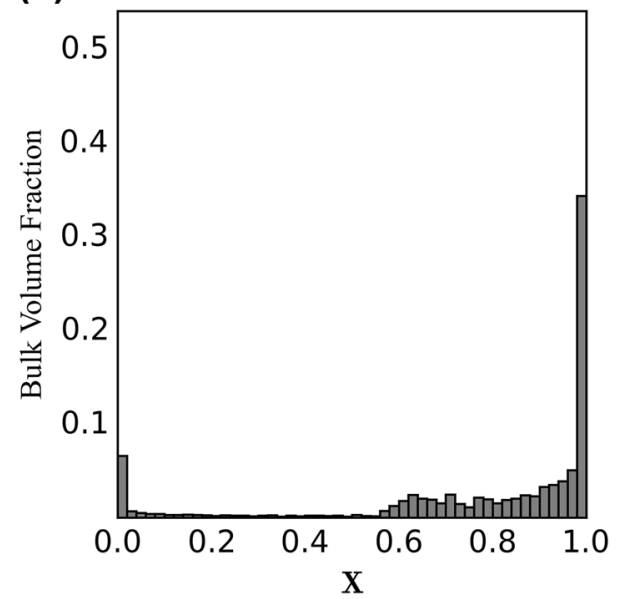

(a)

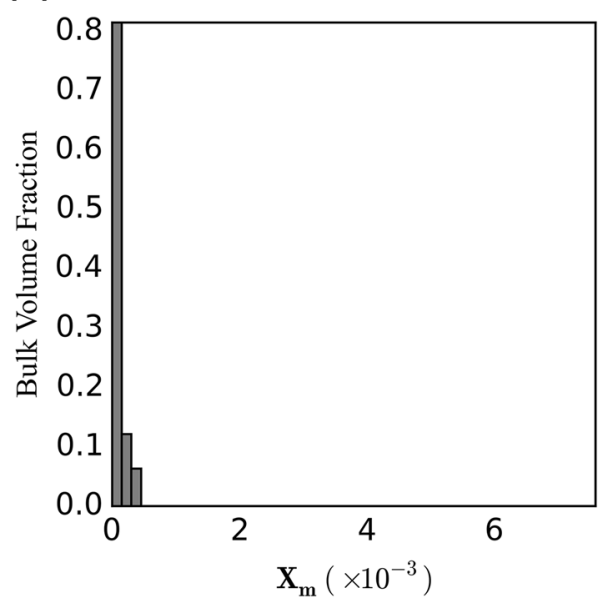

(a)

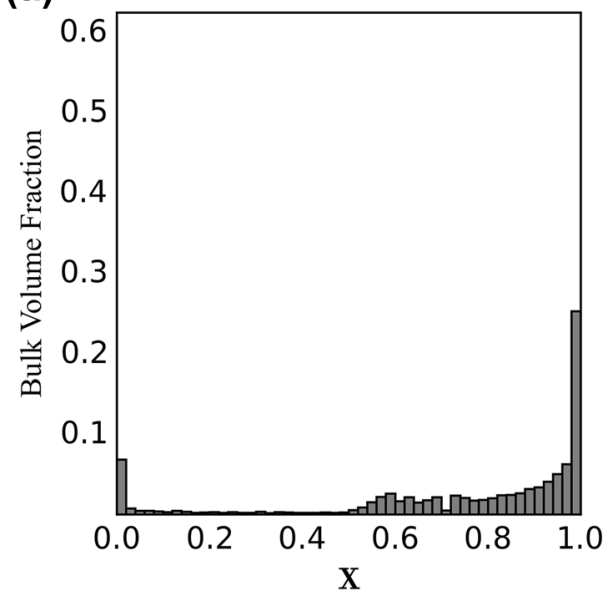

(b)

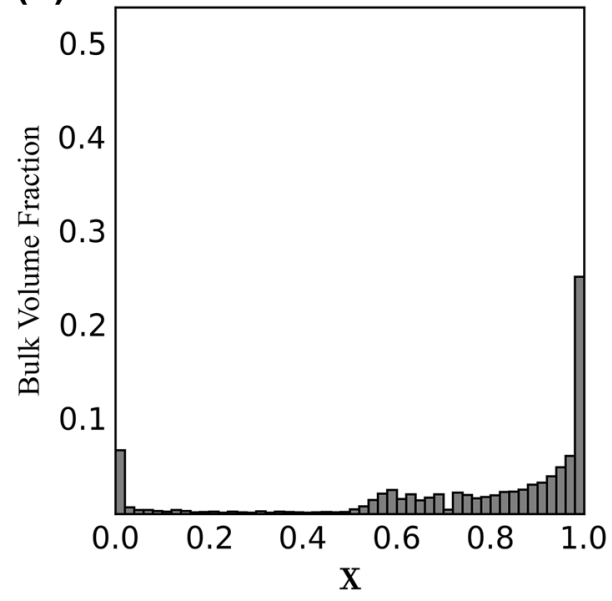

(b)

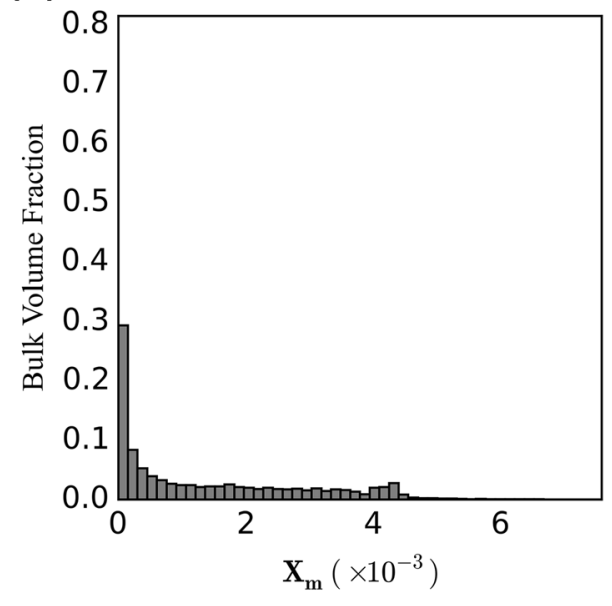

(b)

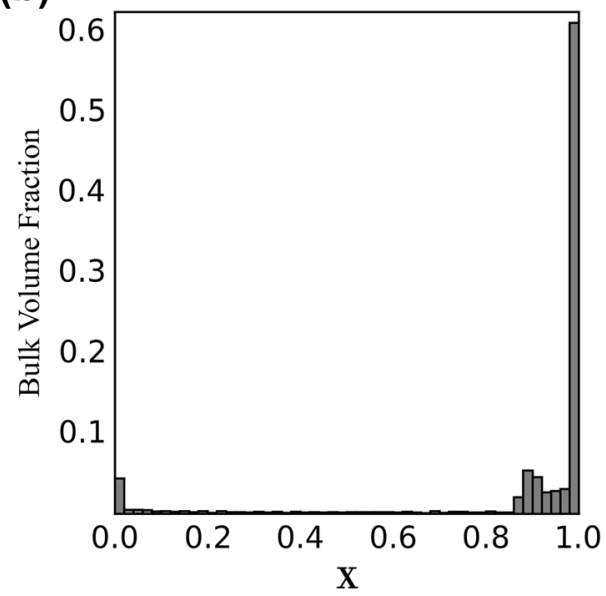


Fig. 8 Relative-distribution plots for Hardness obtained for $200 \mathrm{~min}$ heat-soak time and $25 \mathrm{~mm} / \mathrm{s}$ forging velocity at different temperatures: a 1000 ${ }^{\circ} \mathrm{C}$ b $1100{ }^{\circ} \mathrm{C}$
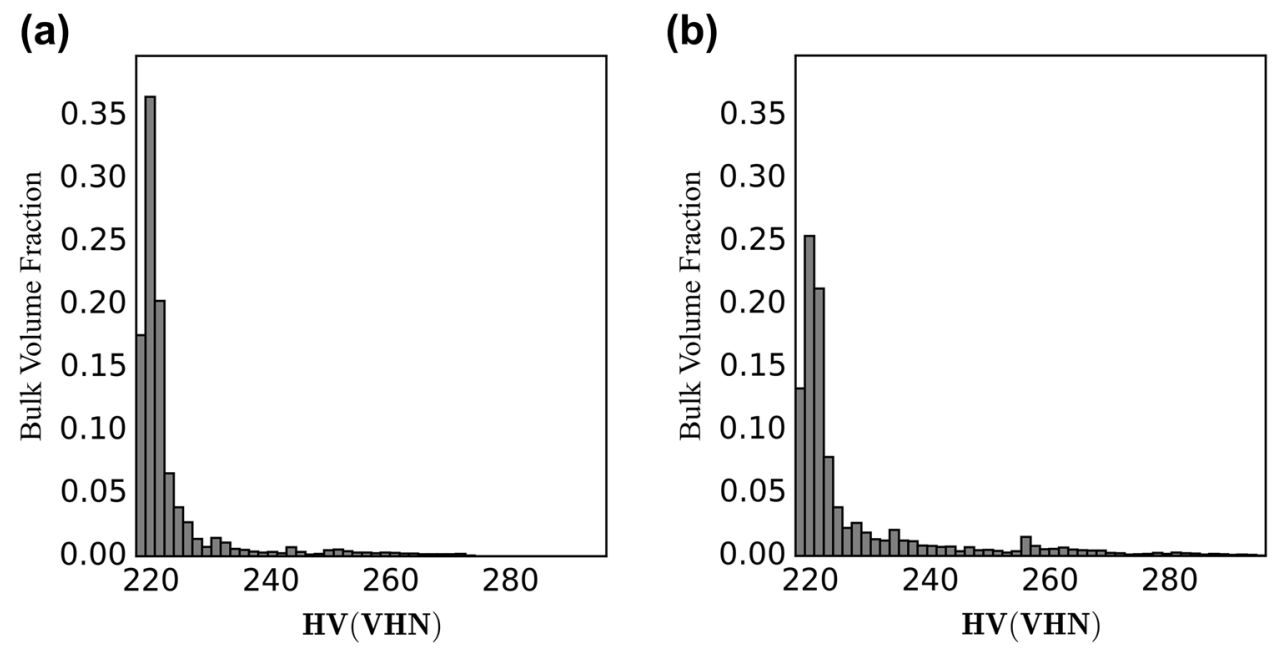

Fig. 9 Relative-distribution plots for final average grain size $\left(D_{f}\right)$ after hot deformation obtained for $200 \mathrm{~min}$ heatsoak time and $1000^{\circ} \mathrm{C}$ forging temperature at different velocities: a $10 \mathrm{~mm} / \mathrm{s}$ b $25 \mathrm{~mm} / \mathrm{s} \mathrm{c}$ $50 \mathrm{~mm} / \mathrm{s} \mathrm{d} 75 \mathrm{~mm} / \mathrm{s}$ (a)

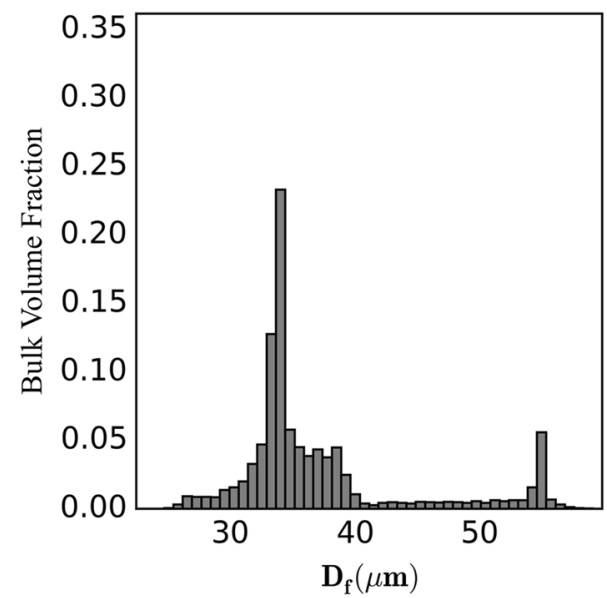

(c)

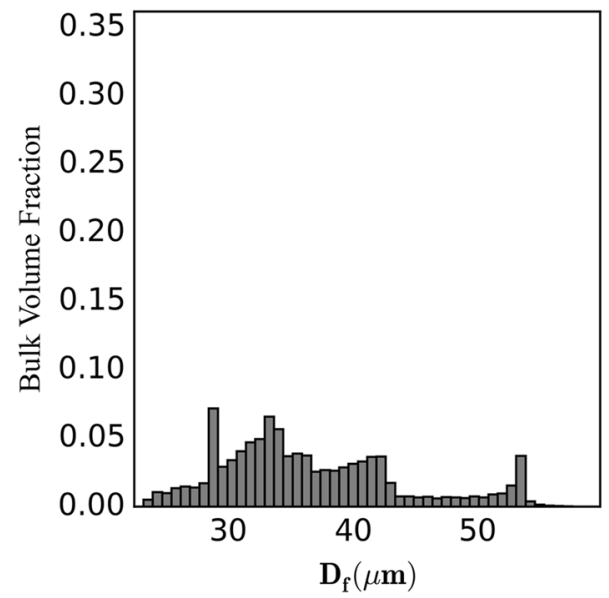

(b)

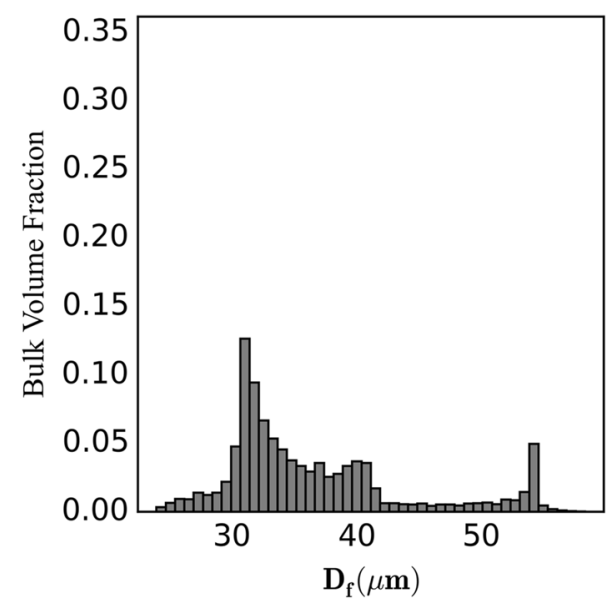

(d)

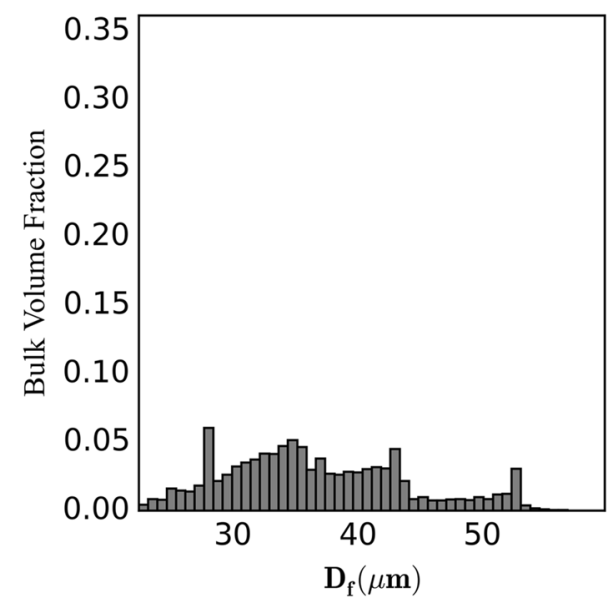

following conditions: $t_{\text {soak }}=100 \mathrm{~min}, T_{\text {forge }}=1100^{\circ} \mathrm{C}$ and $v_{\text {forge }}=25 \mathrm{~mm} / \mathrm{s}$.

Figure $11 \mathrm{~b}-\mathrm{d}$ respectively show the radial variation of recrystallized fraction, hardness and ferrite grain size obtained at the centre of the billet having macrosegregation, and its comparison with the case of billet having a uniform composition. It can be seen that there is not much difference in the recrystallization fraction profile 
Fig. 10 Relative-distribution plots for ferrite grain size $\left(D_{\alpha}\right)$ obtained for 200 min heatsoak time and $1000^{\circ} \mathrm{C}$ forging temperature at different velocities: a $10 \mathrm{~mm} / \mathrm{s}$ b $25 \mathrm{~mm} / \mathrm{s}$ c $50 \mathrm{~mm} / \mathrm{s} \mathbf{d} 75 \mathrm{~mm} / \mathrm{s}$
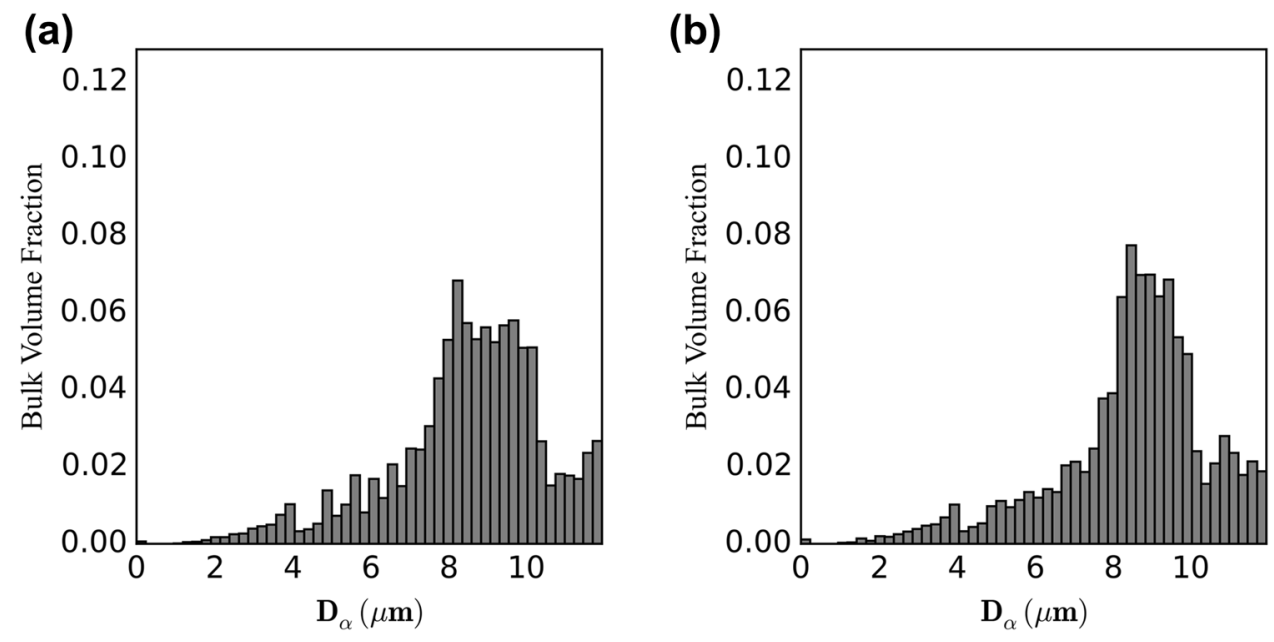

(c)

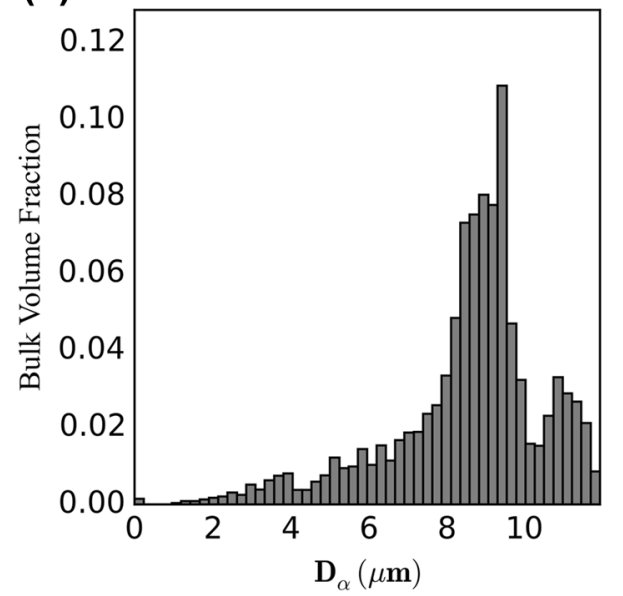

(d)

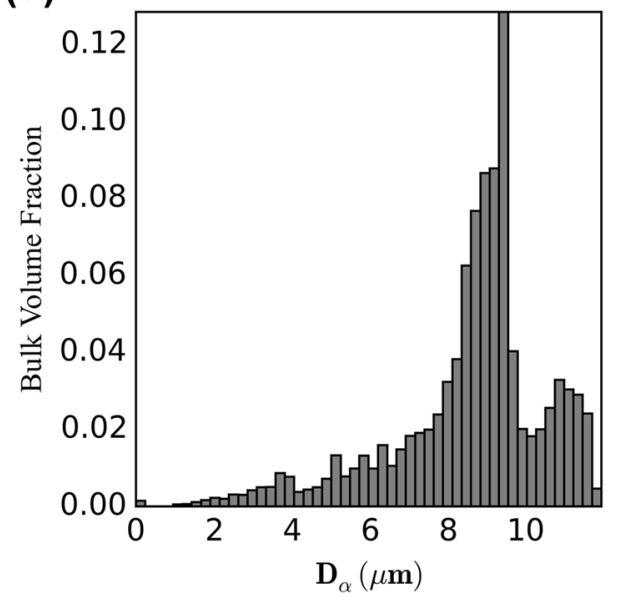

of the two cases closer to the centre, except at the surface where the billet with macrosegregation undergoes more recrystallization. This can be attributed to the high strain at the centre of the billets, due to which both the billets undergo complete recrystallization irrespective of the composition. However, near the surface, the strain is relatively less due to bulging effect, and thus, the effect of composition becomes more prominent. Since there is a higher carbon content at the surface, it leads to a lower activation energy for deformation during DRX and thus enhances DRX kinetics. This is very much in accordance with some of the previous experimental studies that reported the effect of carbon content on DRX [44-46]. On the other hand, there is a marked difference in the final hardness and ferrite grain size variation. As can be seen from Fig. 11c, higher hardness is obtained both at the surface and at the centre of the billet with macrosegregation, whereas at regions in between, the hardness of the billet with macrosegregation is lower than the hardness of the billet with no macrosegregation. This is expected as the high carbon content at the centre and at the surface lead to high hardness values of individual phases than at the centre. Apart from that, the higher solute content at centre and surface leads to suppression of diffusional phases, and assist in martensite formation, which has higher hardness than other phases. Moreover, higher cooling rate at the surface can further assist in the formation of martensite. Similar understanding can be applied to ferrite grain size variation, shown in Fig. 11d. High cooling rates prevalent at the surface leads to the formation of finer ferrite grain size, whereas at the centre, the high solute content completely suppresses ferrite formation.

As can be seen from these results, carrying out this kind of analysis can predict the variation in properties across 
Fig. 11 Radial variation of composition and different microstructural features at the centre of the billet due to macrosegregation: a carbon and manganese $\mathbf{b}$ recrystallization fraction c hardness $(V H N)$ and d ferrite grain size $(\mu \mathrm{m})$
Fig. 12 ICME workflow for design and development for hot forged components (a)

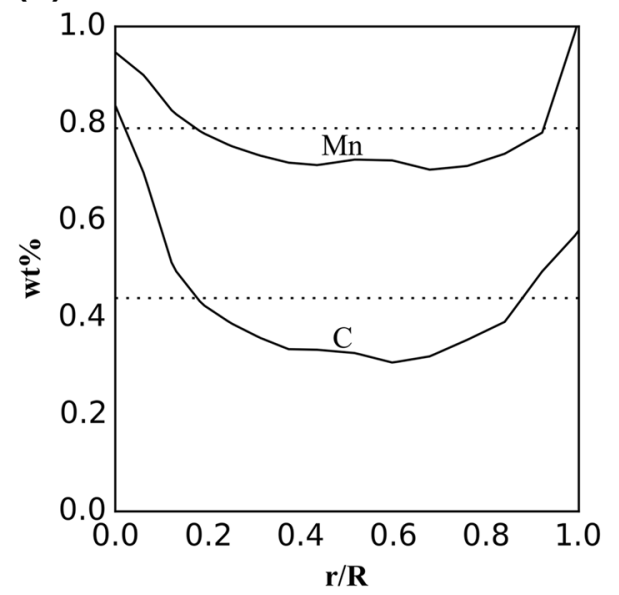

(c)

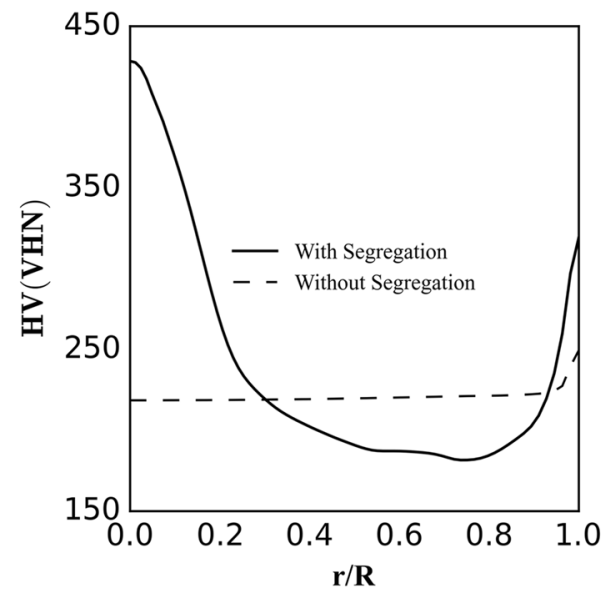

(b)

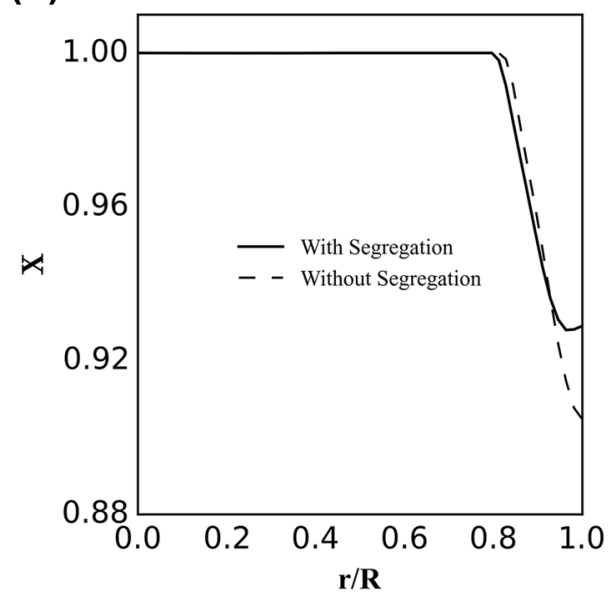

(d)

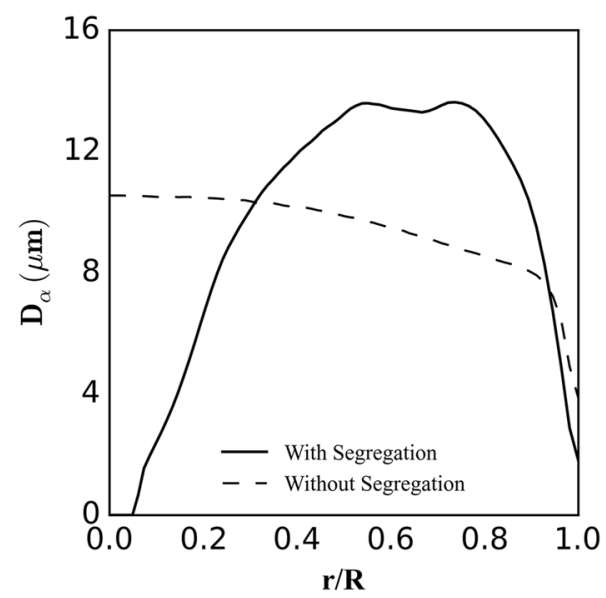

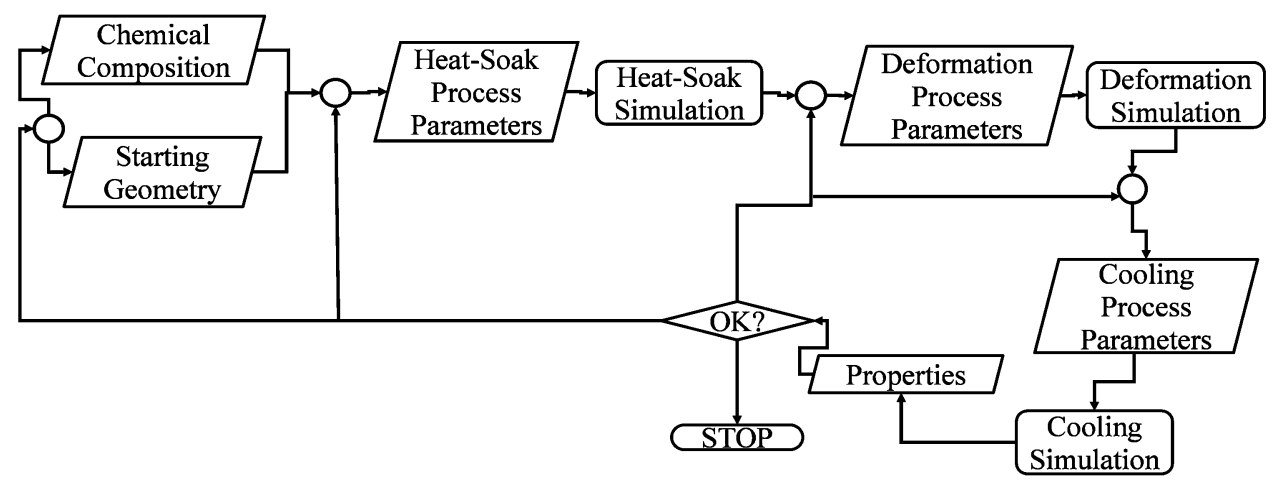

forgings that a particular kind of segregation profile can result in, and thus can help in better process design to achieve the product with controlled quality. Some preventive measures such as chemical composition regulation [23] and adding additional homogenization treatments [24] have been suggested in the literature to reduce the variation in properties of forgings caused due to macrosegregation. However, by capturing the effect of macrosegregation in an analysis like this and by studying the effect of process conditions on the homogeneity of microstructure and properties, like as discussed in Sect. 4.1, the variation in properties of these forgings can 
be further brought down by the proper choice of hot forging process conditions. Moreover, such kind of integrated modelling approach can assist in bringing closer collaboration between otherwise disjointed casting and forging process design, to obtain a controlled product quality collaboratively.

\section{Summary and conclusion}

In this work, an integrated, composition-based, modelling approach has been implemented for hot forging process using different microstructure evolution models available in the literature for each sub-step. The FE models of individual sub-steps of heating, deformation and cooling are developed and integrated by establishing the appropriate information flow between them, leading to the formation of an integrated process modelling framework. The application of such a framework is demonstrated by using it in studies that address two problems of industrial importance for a simple hot upsetting process.

The first study is focussed on exploring the effect of various process parameters on the distribution of microstructure and properties obtained at the end of the process. In order to quantify the distribution and homogeneity of microstructural features and property values obtained under certain process condition, a novel method for representing such information in terms of the bulk-volume fraction of the forged billet has been used. The second study is focussed on exploring the effect of the macrosegregation in the incoming billet, caused during casting, on the final microstructure and properties variation across the forging. The first study highlights the importance of selecting the different substeps process parameters in tandem with each other for getting the desired relative distribution of microstructure features and properties, the cognizance of which is imperative for making better process as well as product design decisions. The second study, on the other hand, brings out the importance of consideration of upstream processes on the variation of microstructure and properties across the hot forged part, thereby underscoring the importance of designing different processes of a manufacturing route in integration with each other. It may be noted that these studies pertain to a relatively simple case of hot upsetting of cylindrical billet where the deformation is broadly uniform. However, in complex forgings, with significant variation in strain and strain rate across the forging, these effects may get further pronounced.

The studies presented in this paper bring out the importance of taking the effects of each of the processes of the manufacturing route into account on the distribution of resultant microstructure and properties, thereby necessitating the adoption of an integrated approach for design and development of products. Such an integrated approach explodes the process design space and gives greater avenues to engineer and enhance the quality of the product in comparison to traditional approaches. Apart from assisting in making better decisions for geometrical and manufacturing design, being able to capture the effect of chemical composition, the modelling framework can also enable proper material selection for the required properties. For brevity purposes, the current work has been demonstrated for a simple case of the hot upsetting process where the deformation is relatively uniform as compared to complex forging and hence easier to analyse. However, the material modelling framework developed in this work is not bound by the geometrical complexity and hence equally applicable for complex industrial hot forging. The framework developed in this work is intended to be automated and used as a module in establishing an ICME workflow for the design and development of forged components, as shown in Fig. 12. Such an ICME workflow shall eventually enable a closer collaboration between otherwise disjointed stages of geometrical designs, material selection and manufacturing process design to collectively obtain a product with a controlled quality.

Acknowledgements The authors would like to acknowledge Mr. K. Ananth Krishnan, CTO, Tata Consultancy services for providing all the necessary resources needed to carry out this work.

\section{Compliance with ethical standards}

Conflict of interest The authors declare that they have no conflict of interest.

Human and animals rights There is no use of humans and/or animals as subject in this research.

\section{References}

1. Oh SI (1982) Finite element analysis of metal forming processes with arbitrarily shaped dies. Int J Mech Sci 24(8):479-493

2. Haque I, Jackson JE, Gangjee T, Raikar A (1987) Empirical and finite element approaches to forging die design: a state-of-theart survey. J Mater Shap Technol 5(1):23-33

3. Duggirala R, Badawy A (1988) Finite element method approach to forging process design. J Mater Shap Technol 6(2):81-89

4. Chan WL, Fu MW, Lu J, Chan LC (2009) Simulation-enabled study of folding defect formation and avoidance in axisymmetrical flanged components. J Mater Process Technol 209(11):5077-5086

5. Espiga F, Jugo A, Anza JJ (1994) Industrial applications of numerical simulation to the design and optimization of forging processes. J Mater Process Technol 45(1-4):81-86

6. Liu Y, Wu Y, Wang J, Liu S (2018) Defect analysis and design optimization on the hot forging of automotive balance shaft 
based on 3D and 2D simulations. Int J Adv Manuf Technol 94(5-8):2739-2749

7. Tomov B, Radev R, Gagov V (2004) Influence of flash design upon process parameters of hot die forging. J Mater Process Technol 157-158:620-623

8. Vazquez V, Altan T (2000) Die design for flashless forging of complex parts. J Mater Process Technol 98(1):81-89

9. Duggirala R (1989) Design of forging dies for forming flashless ring gear blanks using finite element methods. J Mater Shap Technol 7(1):33-47

10. Kim H-Y, Kim J-J, Kim N (1994) Physical and numerical modeling of hot closed-die forging to reduce forging load and die wear. $J$ Mater Process Technol 42(4):401-420

11. Yang TS, Hwang NC, Chang SY (2007) The prediction of maximum forging load and effective stress for different material of bevel gear forging. J Mech Sci Technol 21:1566-1572

12. Politis DJ, Politis NJ, Lin J, Dean TA (2018) A review of force reduction methods in precision forging axisymmetric shapes. Int J Adv Manuf Technol 97(5-8):2809-2833

13. Janga YS, Ko DC, Kim BM (2000) Application of the finite element method to predict microstructure evolution in the hot forging of steel. J Mater Process Technol 101:85-94

14. Wasle G, Lind C, Buchmayr B, Sommitsch C (2002) FEM-gekoppelte Simulation der Mikrostruktur bei Umformprozessen. In: Tagungsband zum XXI. Verformungskundlichen Kolloquium, Leoben. Montanuniv. VKH, Leoben, pp 65-73

15. Bontcheva N, Petzov G (2003) Microstructure evolution during metal forming processes. Comput Mater Sci 28:563-573

16. Serajzadeh S, Mirbagheri SMH, Taheri AK, Zebarjad SM (2004) Modelling of metal flow during hot forging with regard to microstructural aspects. Int J Mach Tools Manuf 44:1537-1545

17. Lin YC, Chen MS, Zhong J (2008) Numerical simulation for stress/strain distribution and microstructural evolution in $42 \mathrm{CrMo}$ steel during hot upsetting process. Comput Mater Sci 43:1117-1122

18. Schmitz GJ, Prahl U (2012) Integrative computational materials engineering: concepts and integration of a modular simulation platform. Wiley, Weinheim

19. Mkaddem A, Huguet A, Mansori ME (2010) Recrystallisation of austenite grain when non-isotherm steel working: effects of thermal kinetics and deformation-based mechanisms. Mater Des 31:4808-4815

20. Taherizadeh A, Najafizadeh A, Shateri R, Jonas JJ (2006) Comparison of mechanical and metallurgical properties of hollow and solid forged products. J Mater Process Technol 178:181-187

21. Irani M, Taheri AK (2008) Effect of forging temperature on homogeneity of microstructure and hardness of precision forged steel spur gear. Mater Chem Phys 112:1099-1105

22. Thornton $P$, Colangelo VJ (1976) Variation of mechanical properties in large steel forgings. Metall Trans B 7(3):425-433

23. Pickering EJ, Bhadeshia HKDH (2014) The consequences of macroscopic segregation on the transformation behaviour of a pressure-vessel steel. J Press Vessel Technol 136:031403

24. Yan G, Han L, Li C, Luo X, Gu J (2017) Effect of macrosegregation on the microstructure and mechanical properties of a pressure-vessel steel. Metall Mater Trans A 48(7):3470-3481

25. Leslie WC (1981) The physical metallurgy of steels. McGraw Hill, New York

26. Lee SJ, Lee YK (2008) Prediction of austenite grain growth during austenitization of low alloy steels. Mater Des 29(9):1840-1844

27. Hernandez CA, Medina SF, Ruiz J (1996) Modelling austenite flow curves in low alloy and microalloyed steels. Acta Mater 44(1):155-163

28. Medina SF, Hernandez CA (1996) Modelling of the dynamic recrystallization of austenite in low alloy and microalloyed steels. Acta Mater 44(1):165-171
29. Sellars CM, Tegart WJM (1966) La relation entre la résistance et la structure dans la deformation à chaud. Mém Sci Rev Metall 63:731-746

30. Kang Y, Liu D (2009) Microstructure refinement of steels by TSCR technology. In: Weng Y (ed) Ultra-fine grained steels. Springer, Heidelberg, pp 137-234

31. Kirkaldy JS, Venugopalan D (1984) Prediction of microstructure and hardenability in low alloy steels. In: Marder AR, Goldenstein JI (eds) Phase transformations in ferrous alloys. AIME, New York, pp 125-148

32. Koistinen DP, Marburger RE (1959) A general equation prescribing the extent of the austenite-martensite transformation in pure iron-carbon alloys and plain carbon steels. Acta Metall 7(1):59-60

33. Andrews KW (1965) Empirical formulae for the calculation of some transformation temperatures. J Iron Steel Inst 203:721-727

34. Li MV, Niebuhr DV, Meekisho LL, Atteridge DG (1998) A computational model for the prediction of steel hardenability. Metall Mater Trans B 29(3):661-672

35. Steven W, Haynes AG (1956) The temperature of formation of martensite and bainite in low-alloy steel. J Iron Steel Inst 183:349-359

36. Suehiro $M$, Sato $K$, Tsukano $Y$, Yada $H$, Senuma T, Matsumura $Y$ (1987) Computer modeling of microstructural change and strength of low carbon steel in hot strip rolling transactions. ISIJ Int 27:439-445

37. Parrish G (1999) Carburizing: microstructures and properties. ASM International, Materials Park

38. Bain EC (1939) Functions of the alloying elements in steel. ASM International, Materials Park

39. Irvine KJ, Pickering FB, Garstone J (1960) The effect of composition on the structure and properties of martensite. J Iron Steel Inst 196:66-81

40. Grange RA, Hribal CR, Porter LF (1977) Hardness of tempered martensite in carbon and low-alloy steels. Metall Trans A 8(11):1775-1785

41. Abaqus 6.14. User's guide. Dassault Systèmes Simulia, Providence, RI, USA

42. Essadiqi E, Jonas JJ (1988) Effect of deformation on the austenite-to-ferrite transformation in a plain carbon and two microalloyed steels. Metall Trans A 19(3):417-426

43. Mangal S, Nirgudkar H, Tennyson G (2018) Macrosegregation of multicomponent steel in round billet continuous caster. In: Roy T, Bhattacharya B, Ghosh C, Ajmani S (eds) Advanced high strength steel. Lecture notes in mechanical engineering. Springer, Singapore, pp 195-203

44. Medina SF, Hernandez CA (1996) General expression of the Zener-Hollomon parameter as a function of the chemical composition of low alloy and microalloyed steels. Acta Mater 44(1):137-148

45. Elwazri AM, Wanjara P, Yue S (2004) Effect of carbon content on dynamic recrystallization behaviour of plain carbon steels. Can Metall Q 43(4):507-512

46. Serajzadeh S, Taheri AK (2002) An investigation on the effect of carbon and silicon on flow behavior of steel. Mater Des 23:271-276

Publisher's Note Springer Nature remains neutral with regard to jurisdictional claims in published maps and institutional affiliations. 